\title{
Considerações sobre as significações da psicologia clínica na contemporaneidade
}

\author{
Elza Dutra \\ Universidade Federal do Rio Grande do Norte
}

\begin{abstract}
Resumo
Este artigo considera a evolução de significados e conceitos da Psicologia Clínica e suas implicações para as ações do psicólogo dessa área. Para isso baseia-se no pensamento fenomenológico e nas idéias de alguns estudiosos da psicologia, na tentativa de melhor compreender as mudanças ocorridas nos saberes e fazeres do psicólogo clínico. A análise empreendida confirma a importância do compromisso social do psicólogo na sua prática e sugere que a postura clínica repousa não só na formação teórico-técnica, mas, sobretudo, na ética da escuta do não-dito e do interditado.
\end{abstract}

Palavras-chave: psicologia clínica; clínica fenomenológica; compromisso social; escuta clínica; ética.

\begin{abstract}
Considerations on the meanings of clinical psychology in our times. The aim of this article is to discuss the evolution of the meanings and concepts of Clinical Psychology and its implication for the psychologists in this area. The discussion is based on the concepts of the phenomenological approach and the ideas of authors in Psychology and leads to a better understanding of the changes that have taken place on psychological knowledge and practices. Such analysis points to the relevance of social commitment from the clinical psychologist and suggests that the accomplishment of his work lies not only on a proper theoretical and technical knowledge, but above all on an ethical attitude regarding the listening of what is unsaid and censored.
\end{abstract}

Keywords: clinical psychology; clinical phenomenology; social commitment; clinical listening; ethics

$\mathrm{N}$ este artigo pretendemos abordar alguns aspectos pertinentes à área da Psicologia Clínica enquanto um campo de produção de saberes e da prática do psicólogo. Tomamos como ponto de partida a evolução histórica deste campo de atuação, ancorando as nossas argumentações em estudos desenvolvidos por autores brasileiros que se debruçaram sobre as mudanças ocorridas nessa área nos últimos anos. Ao mesmo tempo, fazemos considerações acerca de algumas noções pertinentes à prática clínica, como a escuta clínica, sofrimento psíquico, subjetividade e a possibilidade de aplicação dessa dimensão da psicologia aos novos campos de atuação do psicólogo na contemporaneidade, fundamentando as nossas considerações em idéias e concepções originadas tanto no campo da psicologia, quanto no pensamento fenomenológico, através das idéias de Martin Heidegger.

A maior inspiração para este trabalho nasceu da atividade clínica de plantão psicológico desenvolvida no ProntoSocorro (PS) do maior hospital da rede pública do Rio Grande do Norte, através de um projeto de extensão, em funcionamento há quatro anos. A partir de então, temos pensado nas transformações e evoluções do conceito e significados da Psicologia Clínica, até os dias atuais. E isto ocorre pelo fato de vermos ações como a que nos referimos, num setor de urgência e emergência de um grande hospital público, se caracterizarem como eminentemente clínicas, ainda que extremamente distantes do modelo tradicional de como ainda hoje é representada essa área de atuação. O que é possível se justificar, desde já, pelas intensas e significativas transformações pelas quais a Psicologia Clínica, enquanto campo de atuação e saber do psicólogo, tem atravessado, implicando, muitas vezes, uma verdadeira desconstrução do que se representava e se conceituava como Psicologia Clínica.

Muitos autores brasileiros, entre os quais Féres-Carneiro (1993), Féres-Carneiro e Lo Bianco (2003), Guedes (1992), Lo Bianco, Bastos, Nunes e Silva (1994) vêm apresentando e discutindo, de forma mais extensa, aspectos significativos presentes nas mudanças ocorridas nessa área da psicologia. Entre estas, podemos apontar, por exemplo, a necessidade de se considerar o contexto social, alterações conceituais a respeito da valorização do individual e intrapsíquico, tão criticado nos primórdios da psicologia no Brasil, entendendo-se que, na atualidade, a Psicologia Clínica, como bem afirma FéresCarneiro (2003), "mostra uma área consolidada que se espraia por inúmeros domínios" (p. 116).

A despeito da ampliação da Psicologia Clínica, referida anteriormente pela autora citada, observamos, principalmente ao longo do trabalho que vem se desenvolvendo no Pron- 
to-Socorro (PS) ao qual nos referimos antes, que a prática clínica em instituições hospitalares continua sendo alvo, desde que o psicólogo adentrou nesse espaço, de polêmicas e discussões a respeito da viabilidade de aplicação das atividades clínicas nessas instituições e, principalmente, num PS. Tais discussões têm levado os profissionais da área a um esforço permanente no sentido de caracterizar e diferenciar, sobretudo, a psicologia clínica, da hospitalar. Para ilustrar o que acabamos de dizer, basta ver o grande número de produções teóricas a respeito do assunto, de autores que transitam teórica e metodologicamente e vale dizer, com desenvoltura, nas duas áreas, como, por exemplo, Angerami (1985; 2002a; 2002b; 2003).

$\mathrm{Na}$ maioria das vezes, o discurso que permeia tais discussões ampara-se e fundamenta-se num entendimento da clínica identificada somente pela prática de psicoterapias de longa duração, consultório privado, etc. Questiona-se se tais atividades, próprias da clínica, seriam viáveis num contexto como a instituição hospitalar e mais especificamente, no PS, cujas principais características são a imprevisibilidade e o inusitado. E com tal cenário em vista, como se configurariam, então, o setting terapêutico, assim como a psicoterapia e o diagnóstico, entre outras atividades pertinentes à área da psicologia clínica? E, acima de tudo, o que queremos dizer quando nos referimos à escuta clínica, e como esta se diferencia das demais formas de intervenção do psicólogo nos diversos campos de atuação? São questionamentos dessa natureza que nos conduziram a este artigo, o qual pretende discutir, embora sem a pretensão de aprofundar a questão da evolução da Psicologia Clínica, o que, de certa forma, já vem sendo feito por alguns dos autores antes citados. Ao contrário, as reflexões e considerações desenvolvidas aqui visam, principalmente, alimentar o debate já posto em evidência nos meios acadêmicos acerca dessa temática, ao discutir questões pertinentes ao assunto em foco. Com tal objetivo em mente, é importante nos determos em certos aspectos que traduzem algumas das significações da Psicologia Clínica, o que, inevitavelmente, implica uma perspectiva de desconstrução e reinvenção do modelo clínico tradicional.

\section{Das concepções de clínica na psicologia}

Alguns aspectos marcaram a origem da psicologia clínica e suas representações, ao longo da história da Psicologia. Começando pela etimologia do termo clínica, que nos remete ao significado de à beira do leito, deixando clara a influência do modelo médico nesta área de conhecimento e campo de atuação do psicólogo, e tendo como foco de atenção, a compreensão e o tratamento da doença. A influência desse modelo teve um papel fundamental na práxis do psicólogo no contexto da clínica. Além disso, em termos de representação social do psicólogo clínico, a função deste tem se aproximado daquela exercida pelo médico. Por exemplo, é possível se constatar, ainda hoje, no cotidiano da prática clínica, que muitos procuram esse profissional com a disposição de apresentar o seu sofrimento, problema ou o que quer que seja que assim se apresente. E, ao final, esperar uma solução rápida e eficaz, que atenda à cura do seu mal psíquico, aproximando um sofrimento que é da ordem do psicológico e do simbólico, à doença do físico, e que poderia ser tratado através da prescrição de uma medicação adequada, como o faz o médico. Isto se não quisermos falar, igualmente, de outra imagem, estereotipada, porém representativa deste profissional, considerado como aquele que trata de "doentes mentais", o que, na maioria das vezes, torna-se um fator de impedimento ao se buscar este profissional quando dele se necessita. Não se pode negar, além de tudo, a influência que a área médica legou ao psicólogo clínico, no que respeita ao status social, tão evidente nessa área de atuação, constituindo-se, ainda hoje, num dos principais atrativos para aqueles que almejam uma formação clínica em psicologia.

É possível nos referirmos a uma concepção de clínica tradicional ou clássica, como propõem Lo Bianco et al. (1994), contrapondo-se a uma outra forma de se pensar a Psicologia Clínica, que surge sob a denominação utilizada por esses autores como tendências emergentes. Nesse sentido, alguns estudos têm sido desenvolvidos com o objetivo de caracterizar as práticas clínicas, principalmente aqueles empreendidos pelo Conselho Federal de Psicologia /CFP (1988). Lo Bianco e colaboradores apresentam como principais características da Psicologia Clínica tradicional algumas atividades como: psicodiagnóstico e/ou terapia individual ou grupal; atividades exercidas em consultório particular, em que o psicólogo se apresenta como autônomo ou profissional liberal, atendendo, geralmente, a uma clientela financeiramente abastada. Além disso, tal atividade priorizaria o enfoque intrapsíquico e os processos psicológicos e psicopatológicos do indivíduo, norteada por uma concepção de sujeito abstrato e descontextualizado historicamente. Esta mesma constatação é feita e discutida por Figueiredo (1996), o qual nomeia esta representação social do psicólogo clínico como confusões.

Por sua vez, as práticas clínicas emergentes ou atuais, melhor dizendo, apontariam para um maior interesse e preocupação com o contexto social. Isto implica significativas alterações na concepção de sujeito e, conseqüentemente, novas interpretações das teorias psicoterápicas. A nova concepção de clínica na psicologia passa, então, a buscar uma articulação mais concreta entre a clínica e o social. Podemos dizer que o novo fazer clínico inclui uma análise do contexto social em que o indivíduo está inserido. O referencial teórico, assim, deixa de ocupar o espaço de principal norteador da prática, que passa a ser ocupado pelo compromisso ético do psicólogo. É nesta direção que se dirigem as opiniões de Féres-Carneiro e Lo Bianco (2003), ao dizerem que as mudanças na Psicologia Clínica não ocorrem apenas no que se refere à sua abrangência de aplicações. Estas importam, principalmente, às próprias concepções de sujeito, objeto dessa área da psicologia. E nisso se incluem noções teóricas como subjetividade, individualidade, etc.

Tais considerações sugerem que adotar, na clínica, uma dimensão mais concreta do contexto social implica modificações nos referenciais teóricos que ancoram as práticas clínicas, principalmente no que se refere à noção de subjetividade. É nesta direção que se percebe o crescimento de uma 
tendência na Psicologia Clínica, a qual se centraria na ênfase de uma concepção de subjetividade resultante de uma construção social e histórica. Assim, modifica-se a noção de sujeito e, com ela, a postura diante do ato clínico. Tal movimento em direção ao contexto social constitui-se num movimento teórico-metodológico até então pouco pensado no âmbito da Psicologia Clínica tradicional. E surge da necessidade de construção de um saber que reflita, também, a realidade brasileira, e que possa problematizar as práticas até então ainda não pensadas na dimensão sócio-cultural.

Segundo pesquisa do Conselho Federal de Psicologia $(\mathrm{CFP})^{1}$ realizada com psicólogos brasileiros, o que mais caracterizou a saída da clínica do seu modelo tradicional foi a sua inserção na saúde pública, com o psicólogo clínico passando a atuar em hospitais e ambulatórios gerais e psiquiátricos, nas unidades básicas de saúde, nas escolas, creches e organizações, onde são empreendidas ações de saúde. Posteriormente, com a criação do SUS, Sistema Único de Saúde, o psicólogo passou a se inserir na rede pública de saúde. No entanto, ainda era possível, naquele momento, se observar que a prática exercida nesse contexto e, não raro, ainda nos dias atuais, reproduzia o modelo clínico clássico. Por outro lado, é válido lembrar que tal não acontece somente com o psicólogo, mas também com toda a equipe de saúde, de uma maneira geral, cujos profissionais ainda não recebem uma formação curricular adequada e direcionada para a prática no sistema público de saúde. Basta ver que, somente agora, alguns cursos de medicina têm empreendido alterações curriculares visando à atuação do profissional médico no sistema público de saúde, como é o caso, por exemplo, do curso de medicina na Universidade Federal do Rio Grande do Norte (UFRN).

A despeito do que acabamos de mencionar, as novas aplicações das práticas clínicas, principalmente aquelas desenvolvidas nas unidades básicas de saúde, já caminham no sentido de envolver uma nova concepção de clínica psicológica, a qual passa a constituir-se, baseados em estudos do Conselho Regional de Psicologia-6 $6^{\underline{a}}$ região $(\mathrm{CRP}-06)^{2}$, também, por

ações de baixa complexidade, ampliando-se, assim, para uma percepção da clínica não como sinônimo de ações psicoterápicas especializadas, mas como manejos que previnem as necessidades dos mesmos ou que visam à promoção da saúde. (Bianco et al., 1994, p. 41)

Nessa nova concepção de clínica psicológica, entendese que o ato clínico deve ser contextualizado e refletido, onde quer que este se realize ou onde quer que a clientela esteja. É preciso evitar abstrair o ser humano do contexto em que ele vive; no entanto, considerar o indivíduo no seu contexto não acontece quando o vemos com um psiquismo universal. A clínica contextualizada não significa somente considerar o que se encontra em torno da clientela, tal como o local e tipo de clientela (baixa renda, etc.) ou modus operandi. Envolve, sobretudo, uma postura diante do ser humano e sua realidade social, exigindo, portanto, "uma capacidade reflexiva continuamente exercitada em relação à própria prática", como bem o dizem Lo Bianco et al. (1994, p. 56).

\section{Repensando as noções de sujeito, subjetividade e fenômeno psicológico}

Esta nova forma de se olhar a clínica nos leva a reconhecer, antes de tudo, que a Psicologia Clínica, ou as práticas clínicas, de uma maneira geral, são vistas sob óticas diversas e de acordo com o campo epistemológico que as fundamentam. A esse respeito, Gomes (2003) já afirmara que "cada epistemologia traz em seu bojo sua própria teoria de verdade e estamos novamente lançados nas agruras das ideologias e das retóricas" (p. 52). Para Lévy (2001), reafirmando o mesmo pensamento, as práticas clínicas

devem ser avaliadas em função das posições filosóficas e ideológicas em relação às quais elas se definem e diferenciam; são essas posições fundamentais que lhes dão sentido, sendo em relação a elas que se situam os pontos de ruptura. (p.57)

O campo da clínica, por outro lado, traz à tona a questão sobre o que seja o fenômeno psicológico, a subjetividade ou mundo interno, ao qual nos referimos quando nomeamos a dimensão objeto desse campo de atuação. E dar um nome a essa dimensão tem sido problemático. Bock (2001) desenvolveu estudos nessa direção e verificou a diversidade de significados e definições que o fenômeno psicológico recebia dos psicólogos. E conclui afirmando que "o mundo psicológico é um mundo em relação dialética com o mundo social” (p. 23).

Assim, urge uma redefinição do que seja fenômeno psicológico. Já não cabe a concepção de mundo interno/externo, subjetivo/objetivo, etc., posição já defendida antes por filósofos como Merleau-Ponty e Martin Heidegger. E agora se revelam através das novas direções para onde se movimentam as atuais tendências nesse campo, principalmente pelos representantes da psicologia crítica. Embora não se possa negar que as teorias psicoterápicas, na sua maioria, trazem, em seu bojo, a consideração da dimensão social, ao conceberem a subjetividade como constituída através dos vínculos com o outro, ainda constata-se a prevalência do olhar que enfatiza os processos internos, subjetivos e intrapsíquicos. É possível citar algumas dessas perspectivas, as quais, segundo González-Reys (2001), ainda que contemplem este social, fragmentam e supervalorizam um espaço social específico, tal como os vínculos, referindo-se à psicanálise; a família, na terapia sistêmica, ou supervalorizam o outro individual, nas abordagens humanistas. Por outro lado, Figueiredo (1996) já afirmara a sua convicção sobre a dispersão teórico/prática da psicologia. São lugares epistemologicamente diversos e, muitas vezes, antagônicos, dos sistemas teóricos que compõem o campo de saber da psicologia.

Seria preciso, então, desconstruir o modelo tradicional de clínica, ao qual vimos nos referindo. E desconstruir, no nosso entender, significa, antes de tudo, uma mudança no campo epistemológico. Tal mudança poderia dar lugar a um olhar mais amplo, ao permitir que o psicólogo clínico pense o sujeito diante dele como aquele que se constitui no mundo, numa relação com o mundo natural e social; mundo este que, ao mesmo tempo em que o constitui, também é constituído por ele. Adotar uma nova perspectiva de clínica significa ab- 
sorver uma postura através da qual se expresse um posicionamento ético e político. Como diz Bock (2001), "trabalhar para aliviar o sofrimento psicológico das pessoas exigirá do psicólogo um posicionamento ético e político sobre o mundo social e psicológico" (p. 260). Assim, não importa em que lugar ou espaço o ato clínico aconteça, seja no âmbito privado ou público, numa relação diádica, grupal ou coletiva. Este será sempre um fazer psicológico que se pautará em concepções teóricas e metodológicas que refletirão essa postura diante do sofrimento ou fenômeno psicológico que se coloca diante dele. Melhor dizendo, o ato clínico se pautará muito mais por uma ética do que por referenciais teóricos fechados. É nessa direção que Figueiredo (1996), propõe um sentido diferente para a ética, de acordo com a etimologia do termo éthos, no que se relaciona com o habitar, com a morada, ao afirmar que,

O homem é arremessado num mundo, que ele não escolheu, e aí ele é $\operatorname{como}^{3}$ a abertura ao que deste mundo lhe vem ao encontro, ou seja, ele existe no sentido preciso de ser fora de si mesmo, de "ser o seu fora", vale dizer, de ser-no-mundo. Nessa expressão, "no mundo" não indica um lugar em que se é, mas o próprio modo-de-ser do homem. (p. 44)

Para esse autor, a ética, neste sentido, remeteria para a dimensão humana do si-mesmo, tal como pensado por Heidegger (1999), ou seja, para a dimensão da experiência, do conhecido e do não-conhecido, o qual não poderá ser previsto, conhecido na sua totalidade e que se apresenta ao homem na sua condição de existência.

Por outro lado, não restam dúvidas de que o referencial teórico do psicólogo clínico constitui-se numa das ferramentas com as quais ele constrói o espaço da clínica. Porém, ao mesmo tempo em que necessita desse referencial para visualizar a queixa, problema ou sofrimento do indivíduo, ele precisa se afastar desse mesmo referencial para poder enxergar a singularidade do sujeito, sem correr o risco de impor o seu saber sobre ele. Com isso, entendem-se como as noções de sujeito, subjetividade e as concepções teóricas que embasam o fazer clínico, norteiam esta ação. Tal modo de pensar nos faz considerar a subjetividade como um espaço individual cujas significações sociais constituem a história pessoal desse sujeito e os sentidos que ele atribui ao mundo. Desse modo, acolher o outro no seu sofrimento subjetivo, considerando a dimensão social, significa a des-reificação da sua natureza universal, ao se considerar o sofrimento como um momento do sujeito, com sentidos e significações diferentes para cada um, e de acordo com o seu modo de ser e de viver, não conduzindo, necessariamente, a uma patologia. $\mathrm{O}$ que significa dizer que a prática clínica tem lugar sempre que o sofrimento do sujeito cria uma demanda, mas não necessariamente quando se instala uma patologia. Com esse raciocínio é possível, agora, considerar que o que caracteriza a prática clínica não pode reduzir-se nem ao lugar, consultório; nem ao número de sujeitos ou a sua classe econômica; nem à técnica utilizada ou à patologia diagnosticada. $\mathrm{O}$ diferencial da escuta clínica encontra-se na qualidade da escuta e acolhida que se oferece a alguém que apresenta uma demanda psíquica, um sofrimento, para um outro que se propõe a compreender esta demanda. Representa uma determinada postura diante do outro, entendendo-o como sujeito que pensa, sente, fala e constrói sentidos que se expressam, se criam e se modificam nessa relação de subjetividades, num determinado mundo e num certo momento das suas histórias. Significa, como diz González-Reys (2001), “outorgar à psicoterapia um lugar diferente dentro de outros campos de atividade profissional do psicólogo" (p. 212).

Para Figueiredo (1995), a visão da clínica seria o espaço da escuta do excluído, do interditado, procurando atender a esta demanda. Para ele,

a clínica define-se, portanto, por um "ethos": em outras palavras, o que define a clínica psicológica é a sua ética: ela está comprometida com a escuta do interditado e com a sustentação das tensões e dos conflitos. (p. 40)

Assim, o psicológico, ou seja, o que podemos chamar de fenômeno psicológico, se constituiria, segundo Figueiredo (1996), "como um meta-fenomenal que detém o segredo das condições e dos outros sentidos daquilo que se dá e se configura na experiência” (p. 29). E no que se refere ao psicólogo clínico, este precisa ter "ouvidos para escutar este interditado" (p. 29), o qual, embora constitua a experiência, precisa ser buscado além dela.

Nessa perspectiva de escuta clínica incluem-se não só a demanda do sujeito, no sentido de um desejo em busca da acolhida ao seu sofrimento, mas também implica uma relação intersubjetiva que o sustente. Pensamos que Martin Heidegger, mais uma vez, e de um horizonte ontológico, nos ajuda a entender tal processo. Dialogando com este filósofo, podemos considerar o sujeito na sua dimensão ontológica, como um ser-no-mundo e vivendo numa abertura para este mundo, como ser-com, de relação, o que significa dizer, com um modo-de-ser singular, e cuja subjetividade não se encontra separada do mundo. Pelo contrário, como seres-no-mundo, estamos e somos no mundo de uma forma inseparável, não sendo possível, portanto, se pensar num homem no qual se identifiquem lugares, essências ou estruturas que determinem um dado modo-de-ser no mundo. Além disso, tal pensamento aponta para a característica de fluidez e provisoriedade do humano, condição esta que o impede de ser aprisionado e objetivado em teorias, técnicas ou conhecimentos. É nesse sentido que as palavras de Critelli (1996) se dirigem, ao afirmar que "a vida humana está em perpétuo deslocamento. Viver como homens é jamais alcançar qualquer fixidez” (p. 16). Portanto, o mundo

é uma sutil e poderosa trama de significação que nos enlaça e dá consistência a nosso ser, nosso fazer, nosso saber. Porém, uma trama fluida, que desaparece sob nossos pés tão logo o sentido que ser faz se dilui e, então, nos faz falta. (p. 18)

\section{E continua Critelli (1996):}

A vida humana não tem, em relação a coisa alguma, a possibilidade de uma pertença "confiada". É um viver sem perfeita entrega ou confiança, por obra de uma condição na qual ser foi dado ao homem, e não por qualquer dúvida casual ou 
metodológica. Não podemos confiar em sossegado abandono, porque de tudo irrompe a falha, a falta, a quebra de sentido e de significações.

A experiência humana da vida é, originariamente, a experiência da fluidez constante, da mutabilidade, da inospitalidade do mundo, da liberdade; a segurança não está em parte alguma. E isto não é uma deficiência do existir como homens, mas sua condição, quase como sua natureza. (p. 18)

Seria, portanto, nesse contexto de mundo, da experiência e da provisoriedade do ser humano, que o psicólogo clínico se situaria com a sua escuta do outro. Ao acolher o sofrimento do homem contemporâneo, ele também se encontra implicado nessa condição existencial, ou seja, mergulhado em sua própria angústia de ser na inospitalidade do mundo.

\section{Algumas considerações sobre o sofrimento psíquico na contemporaneidade}

Mas como falar de contexto histórico, social e cultural, como vimos fazendo, se a psicologia clínica, tradicionalmente e ainda hoje, no imaginário das pessoas, inclusive no âmbito da própria psicologia, continua a ser identificada, quase que exclusivamente, através do seu modelo tradicional e cercado de críticas políticas, ideológicas, entre tantas outras? Como introduzir tais dimensões históricas e existenciais num campo de saber e numa práxis na qual a individualidade prevalece e a ordem intrapsíquica dos processos psicológicos ainda são vistos, equivocadamente, como incompatíveis com uma visão de subjetividade que contemple o sujeito como um ser-no-mundo e cuja dimensão histórica e social, antes de somente influenciar, constituem esta subjetividade?

Como o psicólogo clínico acolherá o sofrimento do homem contemporâneo, sem perder de vista os seus espaços epistemológicos e o compromisso social? Pois, como se não bastasse o desamparo que o ser humano carrega intrinsecamente consigo, enquanto ser de existência solitária e finita, e que se vê lançado no mundo tendo que efetuar escolhas e se construir no seu devir, ainda tem que lidar com as vicissitudes da vida moderna, com o terror resultante das intolerâncias religiosas, com o descaso dos poderes públicos com a cidadania. Os mesmos poderes públicos que lançam o cidadão à sua própria sorte, como mostram a conjuntura social, política e econômica à qual este homem moderno encontra-se exposto e ainda mais fragilizado na sua humanidade. Cada vez mais o sujeito percebe-se esmagado pelas pressões que a sociedade contemporânea exerce sobre a sua subjetividade, como se constata pelas desigualdades sociais do mundo globalizado, a violência crescente, esta concretizada não só nos conflitos urbanos, mas também nos confrontos políticos e étnicos internacionais.

Torna-se difícil fechar os olhos ao sofrimento que se espalha pelas cidades do nosso país. Seja nas metrópoles, nas pequenas ou grandes cidades, os nossos olhos enxergam, cada vez mais, o medo estampado nos rostos dos cidadãos. Nas crianças que fazem da rua o seu lar, adotando, muitas, vezes, as drogas, que entorpecem não só os seus corpos, mas também os seus sonhos de criança, de jovem, de um dia ser gente. Na injustiça social que nega a vida e a esperança a milhares de crianças e jovens brasileiros. Vemos o sofrimento gerado pelo desemprego, negando ao pai de família a crença num futuro para si e os seus e o desespero que invade essas existências, fazendo com que se sinta que a vida não vale a pena, inspirando o gesto suicida, cometido pelo jovem, pelo idoso, pelo adulto e também pelas crianças, como nos mostra Dutra $(1998 ; 2000)$. É visível o sofrimento do sertanejo, desolado pela chuva que não chega para molhar a colheita de milho, de feijão, fazendo com que o agricultor do sertão nordestino perca a fé nos céus e na vida, preferindo não mais viver (Dutra, 2003) ${ }^{4}$. Como se pode constatar na vida do homem contemporâneo, a realidade que lhe é imposta exige da psicologia uma reflexão acerca dos seus saberes. É preciso também rever a sua práxis, visando atender a uma demanda que se apresenta não só no contexto da clínica tradicional, pertinente aos consultórios fechados e quase sempre fundamentada em teorias e técnicas engessadas em conhecimentos importados, mas também nas instituições e quaisquer situações em que a subjetividade humana e o seu sofrimento se revelem e assim possam ser acolhidos.

\section{Considerações finais}

Partindo dos argumentos expostos, resta, então, às práticas clínicas, acolher o sofrimento constituinte da existência humana, naquilo que pode ser cuidado e apreendido enquanto vivência subjetiva e reveladora de sentidos. Assim, o ato clínico passa, então, a representar a acolhida a essa demanda, através de um olhar que possa contemplar e alcançar a singularidade das existências, que se vão construindo nos caminhos traçados pelos desejos humanos e seus quereres, e reveladores da sua condição de ser-no-mundo. E acolher significa, acima de tudo, considerar as subjetividades como constituindo-se num mundo em que as dimensões históricas, sociais e culturais exercem o seu papel no processo de subjetivação. Esta seria a ética de uma nova postura clínica: acolher o sofrimento humano, onde quer que se apresente; viver uma relação concebida como reveladora e formadora de sentidos, e a qual expressa e desvela os modos-de-ser num determinado tempo e história das existências. Para isso, é necessário que este profissional, o psicólogo clínico, esteja existencialmente disponível e, de certa forma, instrumentalizado para estabelecer esse tipo de relação com o outro. Tal pensamento nos remete à formação desse profissional, que passa, necessariamente, pela academia, pelos bancos das universidades, pelo conhecimento adquirido nos clássicos da literatura psicológica, pelas atividades de pesquisa e práticas supervisionadas. No entanto, existe uma dimensão ética, tal como já sugerida por Figueiredo (1996), que não se adquire somente no estudo da ética, enquanto disciplina que compõe os currículos ou códigos de ética; ou seja, no âmbito do conhecimento teórico-técnico. Esta dimensão ética, que envolve as relações do homem com o mundo, e que implica valores, princípios e visão de mundo, repousa nas atitudes, no modo de ser de cada um e que Figueiredo (1993), chama de conhecimento tácito. Este é definido por ele como 
o seu saber de ofício, no qual as teorias estão impregnadas pela experiência pessoal e as estão impregnando numa mescla indissociável; este saber de ofício é radicalmente pessoal, em grande medida intransferível e dificilmente comunicável. (p. 91)

Podemos dizer que essa forma de ser e fazer, se reflete no olhar que lançamos sobre a realidade do mundo que nos cerca, exigindo de cada um de nós o compromisso social com a realidade na qual estamos mergulhados. Significa pensar o mundo vivido e a realidade, nossa e a do outro que acolhemos, não só com a visão da provisoriedade da existência, mas também com o olhar da diversidade, da pluralidade e complexidade que constituem a natureza humana, porém sem perder de vista a singularidade que caracteriza a condição humana. Neste ponto nos identificamos com o pensamento de Figueiredo (1993), quando ele sugere que se pense o psicólogo "como um profissional do encontro" (p. 93). Para o psicólogo, neste caso, e com muita pertinência, o psicólogo clínico, este encontro significaria, nas palavras do autor citado

a nossa disponibilidade para a alteridade nas suas dimensões de algo desconhecido ${ }^{5}$, desafiante, diferente; algo que no outro nos pro-pulsiona e nos alcança; algo que do outro se impõe a nós e nos contesta, fazendo-nos efetivamente outros que nós mesmos. (p. 93)

Nesse sentido, é pertinente o questionamento que faz Figueiredo (1996), sobre se o psicólogo clínico deveria ser concebido como um ofertador de bens ou como um "dispositivo terapêutico, mas também histórico? Talvez o clínico seja a escuta de que o nosso tempo necessita para ouvir a si mesmo naquilo em que lhe faltam as palavras" (p. 40). Quem sabe, este seja um dos caminhos por onde a Psicologia Clínica deva seguir para se constituir, verdadeiramente, numa via de acesso ao sofrimento e à alteridade, podendo, assim, reconciliar-se com a escuta do humano na sua condição de ser-no-mundo.

\section{Referências}

Angerami, V. A.- Camon. (1985). Psicoterapia existencial: noções básicas. São Paulo: Traço.

Angerami, V. A. - Camon. (2002a). Psicologia da saúde. São Paulo: Pioneira Thomson.

Angerami, V. A. - Camon. (2002b). (Org.), Psicoterapia fenomenológico-existencial. São Paulo: Pioneira Thomson.
Angerami, V. A. - Camon. (2003). A psicoterapia diante da drogadicção. A vida nos drogados. São Paulo: Pioneira Thomson.

Bock, A. M. B. (2001). A psicologia sócio-histórica: uma perspectiva crítica em psicologia. In A. M. B. Bock, M. G. M. Gonçalves, \& O. Furtado (Orgs.), Psicologia sócio-histórica: uma perspectiva crítica em Psicologia (pp. 1535). São Paulo: Cortez.

Critelli, M. D. (1996). Analítica do sentido. Uma aproximação e interpretação do real de orientação fenomenológica. São Paulo: EDUC / Brasiliense.

Dutra, E. (1998). Reflexões existenciais e psicossociais do suicídio de adolescentes. Psicologia em Estudo, 3(2), 81-91.

Dutra, E. (2000). Compreensão de tentativas de suicídio de jovens sob o enfoque da Abordagem Centrada na Pessoa. Tese de Doutorado não-publicada, Instituto de Psicologia, Universidade de São Paulo, São Paulo.

Dutra, E. (2002). Comportamentos autodestrutivos em crianças e adolescentes. Algumas orientações que podem ajudar a identificar e prevenir. In C. S. Hutz (Org.), Situações de risco e vulnerabilidade na infância e adolescência: aspectos teóricos e estratégias de intervenção (pp. 53-87). São Paulo: Casa do Psicólogo.

Féres-Carneiro, T. (1993). Academia e profissão em Psicologia Clínica: da relação possível à relação desejável. Psicologia: Reflexão e Crítica, 6(1/2) [supl. 1], 103-105.

Féres-Carneiro, T., \& Lo Bianco, A. C. (2003). Psicologia Clínica: uma identidade em permanente construção. In O. H. Yamamoto \& V. V. Gouveia (Orgs.), Construindo a Psicologia brasileira: desafios da ciência e prática psicológica (pp. 99-119). São Paulo: Casa do Psicólogo.

Figueiredo, L. C. (1993). Sob o signo da multiplicidade. Cadernos de Subjetividade, $1,89-95$.

Figueiredo, L. C. (1996). Revisitando as psicologias. Da epistemologia à ética das práticas e discursos psicológicos. São Paulo / Petropólis: EDUC / Vozes.

Gomes, W. B. (2003). Pesquisa e prática em psicologia no Brasil. In O. H. Yamamoto \& V. V. Gouveia (Orgs.), Construindo a Psicologia brasileira: desafios da ciência e prática psicológica (pp. 23-59). São Paulo: Casa do Psicólogo.

González-Rey, F. L. (2001). O enfoque histórico-cultural e seu sentido para a psicologia clínica: uma reflexão. In A. M. B. Bock, M. G. M. Gonçalves, \& O. Furtado (Orgs.), Psicologia sócio-histórica: uma perspectiva crítica em Psicologia (pp. 193-214). São Paulo: Cortez.

Guedes, M. C. (1992). Atuação do psicólogo clínico: análise de dissertações em periódicos brasileiros e de dissertações e teses defendidas no país no período 1980/92. In Conselho Federal de Psicologia (Org.), Psicólogo brasileiro: construção de novos espaços (pp. 11-24). Campinas: Átomo.

Heidegger, M. (1927/1999). Ser e tempo ( $8^{\mathrm{a}}$ ed, v. I e II). Petrópolis: Vozes.

Lévy, A. (2001). Ciências clínicas e organizações sociais: sentido e crise de sentido. Belo Horizonte: Autêntica/FUMEC.

Lo Bianco, A. C., Bastos, A. V. B., Nunes, M. L. T., \& Silva, R. C. (1994). Concepções e atividades emergentes na psicologia clínica: implicações para a formação. In Conselho Federal de Psicologia (Org.), Psicólogo brasileiro: práticas emergentes e desafios para a formação (pp. 7-76). São Paulo: Casa do Psicólogo. 
1 CFP (1993). Atribuições profissionais do psicólogo no Brasil. Documento encaminhado ao Ministério do Trabalho para reformulação do Catálogo Brasileiro de Ocupações (CBO).

2 CFP (1993). Ministério do Trabalho, Catálogo Brasileiro de Ocupações (CBO).

3 Todos os grifos dessa citação são de seu próprio autor.

4 Relatório técnico de pesquisa aprovado (2003) pelo CNPq: Suicídio de agricultores no RN: aspectos psicossociais e culturais.

5 todos os grifos são do autor.

Elza Dutra, doutora em Psicologia Clínica pela Universidade de São Paulo, é professora no Programa de Pósgraduação em Psicologia, Universidade Federal do Rio Grande do Norte.

Endereço para correspondência: Av. Prof. Olavo Montenegro, 2887; Natal, RN; CEP 59078-330. Tel.: (84)

217-7645. Fax: (84) 215-3589. E-mail: dutra.e@digi.com.br e edutra@digizap.com.br 